\title{
Cinema, Educação e Interculturalidade: Martírio, o filme
}

Intercultural, education, cinema: Martirio (film)

Adriana Fresquet ${ }^{i}$

Wilson Cardoso Juniorii

Faculdade de Educação

Universidade Federal do Rio de Janeiro

\section{Resumo}

No presente trabalho, partimos da educação intercultural crítica para pensar o cruzamento entre cinema, educação e interculturalidade com foco na questão indígena, no contexto do retrocesso das conquistas sociais imposto ao Brasil pelo golpe políticojurídico e midiático de 2016, que resultou no aprofundamento da lógica neoliberal na escola. Nesse sentido, após apresentarmos algumas questões sobre interculturalidade crítica, seguido de consideraçōes sobre cinema como arte, dedicamos especial atenção ao filme Martírio (Brasil; Carelli, Carvalho \& Tita; 2016). Apostamos na sua potência ética, estética e política, multiplicada exponencialmente se transitar pelas salas de aula das escolas do Brasil e de América toda.

Palavras-chave: educação intercutural crítica, cinema, arte, escola, Martírio (filme).

\begin{abstract}
In this work, we started from critical intercultural education to think about cinema, education and interculturality focusing on the indigenous point in the context about the retrocession of social achievements imposed on Brazil by the political-legal and media coup of 2016, which resulted in the deepening of the neoliberal logic in the school. After showing some questions about critic interculturality, followed with considerations about cinema and art, we dedicated special attention to the movie Martírio (Brazil, Carelli, Carvalho \& Tita, 2016). We bet on its ethical, aesthetic and political power, exponentially multiplied by passing through the classrooms of schools in Brazil and all America.
\end{abstract}

Keywords: critical intercultlural education, cinema, art, school, Martirio (film)

O que é possível fazer quando parece que nada podemos fazer num país cada vez mais dominado pelo receituário neoliberal implementado após o golpe político-jurídico e midiático que vem nos sufocando desde 2016? 
A pergunta de Carlos Roberto de Souza ${ }^{1}$ nos remeteu à noção de brechas decoloniais na hegemonia euro-usa-cêntrico que se tornou ainda mais robusta com os rumos que a política nacional tem tomado ultimamente, a fim de enfrentar os efeitos os seus efeitos de "depressão cívica" 2 .

Segundo a autora estadunidense Catherine Walsh (2016), as brechas decoloniais são pouco mais que aberturas ou inícios que surgem a partir de rachaduras existentes na ordem banco/mestiças moderno/colonial. Dependendo de como se plantam as "sementes" de "modos outros" de vida - não-capitalistas, não-consumistas e nãoextrativista - nessas gretas e fissuras, pode-se ir além e alcançar fraturas no poder moderno/colonial que resultem em rupturas e aberturas para a promoção da "cultura da vida" contra a "cultura da morte" representada pela hegemonia monocultural, monorracional e uni-nacional do modelo de civilização ocidental e ocidentalizante.

As brechas se transformam no lugar e no espaço a partir do qual a ação, militância, resistência, insurgência e transgressão são impulsionadas, onde as alianças se constroem, e surgem um modo-outro que se inventa, cria e constrói. Embora as brechas estejam virtualmente nos âmbitos, instituições, estruturas da razão e do poder moderno/colonial, e continuam crescendo dia a dia, costumam passar desapercebidas, sem serem vistas ou escutadas. Isto se deve em grande parte à natureza míope da vida e do viver contemporâneo. (Ibidem, p. 76).

O termo "decolonização" foi cunhado por Walsh para marcar uma forma de pensar distinta daquela pertencente ao processo histórico de descolonização dos povos africanos e asiáticos, via libertação nacional durante a Guerra Fria, em meados do século XX. $O$ colonialismo se refere ao domínio político de povos europeus (os colonizadores) sobre povos não-europeus (os colonizados) pela força e supremacia político-militar do Estado, gestado na Europa a partir do século XVI, como matriz do poder colonial.

A colonialidade advém do colonialismo, mas trata-se de outra forma de dominação que configura formas de ser, conhecer, pensar, crer e agir de acordo com "a lógica de repressão, opressão, despossessão, racismo". Ela impõe a diferença colonial baseada nas noções de raça, racismo e racialidade para manter relações de dominação definidas entre centro e periferia do capitalismo mundial surgido com a modernidade. Na atualidade,

\footnotetext{
1 Comunicação de Carlos Roberto de Souza, presidente da ABPA (Associação Brasileira de preservação Audiovisual/SP), na mesa Plano Nacional de Preservação, do 12a CineOP - Mostra de Cinema de Ouro Preto/MG, em 23/06/2017.

2 Termo utilizado por Marília Franco, professora da Universidade de São Paulo, durante os debates decorrentes da mesa Plano Nacional de Preservação, do 12a CineOP - Mostra de Cinema de Ouro Preto/MG, em 23/06/2017.
} 
essa matriz do poder colonial segue sendo responsável por outras formas de dependência econômica, política, cultural e educacional.

A visão dessa autora faz parte das teorizações do Grupo Modernidade/Colonialidade, formado por um grupo de autores/as americanos, especialmente latino-americanos, que produziu intensamente durante os anos 1990 e a primeira década do século XXI. As produções desse grupo gravitam em torno da ideia-central de que a modernidade e a colonialidade são duas faces da mesma moeda, sendo a colonialidade a sua face oculta, necessária e indissociavelmente constitutiva da modernidade (MIGNOLO, 2010). Por estar intrinsecamente associada à experiência colonial, a modernidade não é capaz de apagá-la e, portanto, não existe modernidade sem colonialidade. O conceito de colonialidade do poder, desenvolvido principalmente pelo peruano Aníbal Quijano (2000), parte da constatação de que as relações de colonialidade nas esferas econômica e política não findaram com a destruição do colonialismo e que formas coloniais de dominação continuam operando por meio das culturas coloniais e pelas estruturas capitalistas da modernidade/colonialidade.

A partir da matriz do poder colonial surgem as coloniadades do saber, do ser e cosmogônica que são produzidas e reproduzidas pelas relações de exploração/dominação/conflito que se baseia principalmente em três tipos de classificação social do capitalismo mundial colonial/moderno: raça, gênero e trabalho. As noções de raça e racismo possui centralidade no pensamento desse coletivo, sendo compreendidas como princípio da construção da diferença, da superioridade e da pureza de sangue da raça branca que estrutura as múltiplas hierarquias que se sobrepõem no sistema-mundo.

Segundo o colombiano Santiago Castro-Gómez (2005), a noção de diferença pela ideia de superioridade da raça branca, construída pelo "imaginário da brancura", foi o primeiro grande discurso universalista dos tempos modernos. Para ele o mito racista engendra um padrão monocultural que não se refere apenas a características ligadas a cor/etnia, mas envolve também normatizações quanto às categorias de classe social (classe média), gênero (masculino), sexualidade (heterossexuais), religião (cristãs) etc.

(...) el imaginario de la blancura producido por el discurso de la pureza de sangre fue una aspiración internalizada por todos los sectores sociales de la sociedad colonial y fungió como el eje alrededor del cual se construyó (conflictivamente) la subjetividad de los actores sociales. Ser «blancos» no tenía que ver tanto con el color de la piel como con la escenificación personal de un imaginario cultural tejido por creencias religiosas, tipos de vestimenta, certificados de nobleza, modos de comportamiento y (esto es muy importante) formas de producir y transmitir conocimientos (Ibidem, p. 60). 
Do ponto de vista educacional, o pensamento decolonialista incide na produção de conhecimentos destinada a dar visibilidade a saberes encobertos pelos currículos oficiais e hegemônicos, de maneira a "dar ouvidos às vozes silenciadas que constroem seus conhecimentos à margem em movimentos de sobrevivência ou resistência." (STRECK, 2012; p. 18-19).

No presente trabalho, partimos das Leis no $11.645 / 2008^{3}$, no $13.006 / 2014^{4}$, no $13.415 / 2017^{5}$ e $13.278 / 2016{ }^{6}$, ainda referentes da LDBEN 9.394/1996, para pensar o cruzamento entre cinema e interculturalidade na educação escolar com foco na questão indígena que, mais do que nunca, se tornou premente com o poderio do agronegócio e o discurso ruralista que mobiliza e renova velhos arquivos coloniais para atacar da forma desumana os direitos dos Povos Indígenas conquistados com a Constituição de 1988 que (ainda que não pareça) se encontra em vigência.

No contexto de retrocesso político-educacional em que nos encontramos, cremos que esse amparo legal, restos de um Estado não existe mais, podem ser tomadas como brechas decoloniais na lógica neoliberal aplicada à educação básica. Nesse sentido, após apresentarmos nosso entendimento sobre educação intercultural e interculturalidade crítica, seguido de consideraçōes sobre cinema como arte na perspectiva da educação intercultural crítica, dedicamos especial atenção ao filme Martírio (2016) por compreendermos ser ele uma "semente" preciosa de um modo outro de vida não-capitalista, não-colonialista e não-extrativista que deve ser plantada interculturalmente nas brechas decoloniais da educação brasileira.

\section{Educação interculltural e interculturalidade crítica}

\footnotetext{
${ }^{3}$ Art. 26-A. Nos estabelecimentos de ensino fundamental e de ensino médio, públicos e privados, torna-se obrigatório o estudo da história e cultura afro-brasileira e indígena. (Redação dada pela Lei no 11.645, de 2008).

$\S 1^{\circ}$ O conteúdo programático a que se refere este artigo incluirá diversos aspectos da história e da cultura que caracterizam a formação da população brasileira, a partir desses dois grupos étnicos, tais como o estudo da história da África e dos africanos, a luta dos negros e dos povos indígenas no Brasil, a cultura negra e indígena brasileira e o negro e o índio na formação da sociedade nacional, resgatando as suas contribuições nas áreas social, econômica e política, pertinentes à história do Brasil. (Redação dada pela Lei n 11.645, de 2008).

$\S 2$ ㅇ Os conteúdos referentes à história e cultura afro-brasileira e dos povos indígenas brasileiros serão ministrados no âmbito de todo o currículo escolar, em especial nas áreas de educação artística e de literatura e história brasileiras. (Redação dada pela Lei no 11.645, de 2008).

(Disponível em: http://www.planalto.gov.br/ccivil 03/leis/L9394.htm. Acesso em 07/07/2017).

${ }^{4}$ Art. 26. $\S 8^{\circ}$ A exibição de filmes de produção nacional constituirá componente curricular complementar integrado à proposta pedagógica da escola, sendo a sua exibição obrigatória por, no mínimo, 2 (duas) horas mensais. (Incluído pela Lei no 13.006, de 2014)

(Disponível em: http://www.planalto.gov.br/ccivil 03/leis/L9394.htm. Acesso em 07/07/2017)

${ }^{5}$ Art. $26 / \S 2$ o 0 ensino da arte, especialmente em suas expressões regionais, constituirá componente curricular obrigatório da educação básica. (Redação dada pela Lei no 13.415, de 2017).

(Disponível em: http://www.planalto.gov.br/ccivil 03/leis/L9394.htm. Acesso em 07/07/2017)

${ }^{6} \mathrm{Art} .26 / \S$ 6o As artes visuais, a dança, a música e o teatro são as linguagens que constituirão o componente curricular de que trata o § 2 o deste artigo. (Redação dada pela Lei no 13.278, de 2016).

(Disponível em: http://www.planalto.gov.br/ccivil 03/leis/L9394.htm. Acesso em 07/07/2017)
}

Revista Digital do LAV - Santa Maria - vol. 10, n. 2, p. 120 - 139 - mai./ago. 2017 ISSN 1983 - 7348

http://dx.doi.org/10.5902/1983734828951 
A Lei $11.645 / 2008$, que torna obrigatório o estudo da história e cultura afro-brasileira e indígena no âmbito de todo o currículo escolar, ainda se mantém mesmo após a onda ultra-conservadora que tomou conta da educação brasileira com o golpe político-jurídicomidiático de 2016.

Essa lei é uma conquista dos movimentos sociais, especialmente do movimento negro no Brasil e, tanto como antes, continua sendo objeto de disputa de sentidos sobre a relação entre educação e multiculturalismo. Ela não garante por si só uma perspectiva de rompimento com a colonialidade de saber que grassa em nossas escolas, pois em torno dela encontramos distintas perspectivas que vão desde o olhar da diversidade cultural pelo exotismo e pelo folclore até outras mais críticas de desafio a estereótipos que problematizam processos de construção de identidades dos/as estudantes a partir do reconhecimento das diferenças na escola.

No Brasil, apesar de não haver consenso acerca da diferença de sentidos entre os termos multiculturalidade (termo predominante nos países de língua inglesa) e interculturalidade (termo predominante nas Américas Central e do Sul), é possível compreender que o multiculturalismo possui um sentido descritivo destinado a caracterizar a formação multicultural de cada contexto específico (com o reconhecimento, respeito e valorização de grupos minoritários e discriminados), semelhante ao entendimento dos termos diversidade cultural e pluralidade cultural - ou seja, trata-se de um indicador da realidade de coexistência de diversos grupos culturais na mesma sociedade (FORQUIN, 2000).

A interculturalidade vai além da mera descrição e prescreve maneiras de atuar e intervir na dinâmica social, pois ela é indicativa de um conjunto de propostas de convivência entre culturas diferentes, independente de suas adjetivações (FLEURY, 2006).

Do ponto de vista da relação entre currículo e cultura/s, os debates e reflexões a esse respeito compreendem concepções que variam quanto a sua capacidade de promover ou obstaculizar processos de construção da cidadania de grupos cultural e racialmente diversificados do padrão monocultural (ocidentalocêntrico e androcêntrica) que rege os currículos escolares em detrimento de outros saberes e culturas.

Esse saber tem mantido a sua hegemonia por meio da blindagem conceitual sobre a noção de conhecimento escolar que tem colonizado os nossos currículos, colocando-os em sintonia com relações de dominação e submissão cultural histórica. Uma de suas características mais marcantes é a naturalização da hegemonia dos conhecimentos de "raiz única" que são apresentados aos/às estudantes sem a sua ancoragem históricocultural, e com status de conhecimento universal, neutro e inquestionável.

De forma contrária, e a partir da interculturalidade, afirmamos o entendimento da necessidade de problematização e des-naturalização desses conhecimentos privilegiados na escola básica (e na universidade), entendendo que processos de naturalização 
camuflam relações de poder que produzem e sustentam preconceitos, discriminações e estereótipos entre pessoas, conhecimentos, saberes e práticas culturalmente diferentes. Entretanto, a lógica intercultural compreende certa polissemia e pode abarcar distintos conjuntos de propostas de convivência entre culturas, ainda que o termo tenha surgido com os movimentos indígenas na América do Sul com o intuito de reivindicar direitos epistêmicos e significar a inter- cultura como inter-epistemologia e pluri/inter-versalidade das cosmologias não-ocidentais, em contraposição a uni-versalidade ocidental.

Adotamos a perspectiva da interculturalidade crítica que se opõe a interculturalidade funcional (TUBINO, 2005; WALSH, 2009). Esta última, surgida no seio das reformas neoliberais dos anos 1990, é regida por uma lógica multicultural que expressa o reajuste estrutural do poder no capitalismo global que passou a reconhecer e incluir as novas etnias sem promover mudança substancial na hegemonia eurocêntrica. Trata-se de um instrumento retórico do neoliberalismo multicultural ou étnico que se apropria da questão da diferença para neutralizar e esvaziar seus significados de transformação e luta.

O intuito da interculturalidade funcional é manter a ordem estabelecida, a conservação do poder e o controle dos conflitos étnicos, apesar de assumir a diversidade cultural como eixo central e promover o seu reconhecimento e inclusão dentro da sociedade e dos Estados nacionais a partir de discurso com ênfase na tolerância. Dessa forma, produz a ilusão da dissolução das desigualdades, pois não trata da assimetria social, da discriminação cultural e dos dispositivos e padrões de poder que mantém a desigualdade (WALSH, 2009, p. 21).

Essa concepção compreende a lógica assimilacionista dos conhecimentos escolares e propõe uma política de universalização da escolarização sem que se coloque em questão o caráter monocultural presente em sua dinâmica. Assim, os conteúdos contrahegemônicos, como aqueles referentes à Lei 11.645/2008, são incorporados e localizados em zonas periféricas do currículo de maneira a não desestabilizar os conhecimentos hegemônicos.

A interculturalidade funcional ou neoliberal reflete a hegemonia usa-europeia por meio de projeções culturais da colonialidade que tem a finalidade de produzir identificações com modos de vida e estruturas de pensamento que se incorporem ao habitus dos atores sociais e naturalizem o imaginário europeu pela produção dos binarismos cartesianos (oriente-ocidente, primitivo-civilizado, irracional-racional, mágico/mítico-científico e tradicional-moderno). A colonialidade reflete o processo histórico de desumanização dos sujeitos colonizados, racializados e colocados "à margem da modernidade, da razão e das faculdades cognitivas" (WALSH, 2009, p. 15).

Santiago Casto-Gomez assinala que essas construções de formas de vida e pensamento geram subjetividades concretas e se encontram entranhadas em estruturas sociais 
objetivas: "leyes de Estado, códigos comerciales, planes de estudio en las escuelas, proyectos de investigación científica, reglamentos burocráticos, formas institucionalizadas de consumo cultural." (2005, p. 22).

De forma oposta, a interculturalidade crítica, concepção desenvolvida inicialmente pelo peruano Fidel Tubino (2005), apresenta-se como uma alternativa à globalização neoliberal e à hegemonia da racionalidade europeia. Ela busca valorizar as diferenças e questionar as desigualdades construídas ao longo da história entre diferentes grupos socioculturais, étnico-raciais, de gênero, orientação sexual que foram historicamente marcadas diferentemente pelo poder instituído do capitalismo mundial - moderno, colonial, patriarcal e eurocêntrico. Essa perspectiva afirma as diferenças como constitutivas da democracia, sendo indispensáveis para a construção de sociedades que sejam capazes de construir relações novas, verdadeiramente igualitárias entre os distintos grupos socioculturais.

Ao contrário de funcionar para manutenção da ordem estabelecida, ela se posiciona pela transformação das estruturas, instituições e relações criadas pelo capitalismo mundial pela via da in-surgência, re-existência e o re-viver a partir daqueles/as que sofreram a submissão e a subalternização histórica e que buscam alternativa à globalização neoliberal e à racionalidade europeia, pensando projetos a partir dos movimentos sociais (construídos a partir de pessoas que sofreram a submissão e subalternização histórica). Por isso, propõe empoderar aqueles/as que foram historicamente inferiorizados/as.

Esse é o sentido do compromisso da interculturalidade crítica com a descolonização do pensamento que por isso investe contra a naturalização do imaginário do invasor europeu, contra a subalternização epistêmica do/a outro/a e contra a negação e o esquecimento de processos históricos não-europeus. Segundo Walsh:

Argumentar não pela simples relação entre grupos, práticas ou pensamentos culturais, pela incorporação dos tradicionalmente excluídos dentro das estruturas (educativas, disciplinares ou de pensamento) existentes, ou somente pela criação de programas "especiais" que permitem que a educação "normal" e "universal" siga perpetuando práticas e pensamentos racializados e excludentes. É assinalar a necessidade de visibilizar, enfrentar e transformar as estruturas e instituições que diferentemente posicionam grupos, práticas e pensamentos dentro de uma ordem e lógica que, ao mesmo tempo e ainda, é racial, moderno-ocidental e colonial. Uma ordem em que todos fomos, de uma maneira ou de outra, participantes (2009, p. 24).

Compreendemos essa teorização como fundamental para problematizar pressupostos eurocêntricos, desconstruir dicotomias hierarquizadas (alta cultura-baixa cultura, 
civilização-primitivismo, cultura erudita-cultura popular) e promover a ecologia de saberes na escola, compreendida como o diálogo horizontal e não-hierárquico entre diferentes conhecimentos/saberes.

A ecologia de saberes compreende a contemporaneidade como simultaneidade de povos e culturas, e baseia-se na copresença radical de diferentes culturas e conhecimentos/saberes na escola, especialmente no currículo, pois do contrário não se supera o racismo epistêmico produzido pelo imaginário de superioridade racial da etnia branca pela imposição dos conhecimentos produzidos pelo ocidente como os únicos legítimos e com capacidade de acesso à universalidade e à verdade - que visa a internalização da inferioridade étnico-racial de sujeitos não-brancos/as (CANDAU e OLIVEIRA, 2010, p. 23).

O racismo epistêmico apresenta-se em sintonia com a hegemonia de concepções epistemológicas, históricas e didáticas fundadas no eurocentrismo e amplamente consolidada no meio educacional brasileiro, tanto na escola básica quanto na academia.

Portanto, na ótica da educação intercultural crítica torna-se necessário problematizar os modos de convivência na escola entre conhecimentos e saberes provenientes de diversas culturas na perspectiva do diálogo, sem com isso visar a eliminação dos conflitos que se apresentam na busca por interações. Isso implica a na necessidade do reconhecimento do outro e na negociação cultural, pois:

(...) Esta interação pode se dar por confronto ou enriquecimento mútuo, e supõe ampliar a nossa concepção de quais conhecimentos devem ser objeto de atenção, entre confluências e tensões, e ser trabalhados na escola, assumindo-se os possíveis conflitos que emergem da interação entre estes saberes. Trata-se de uma dinâmica fundamental para que sejamos capazes de desenvolver currículos que incorporem referentes de diferentes universos culturais, coerentes com a perspectiva intercultural crítica. Nesta perspectiva, é importante conceber a escola como um "espaço vivo, fluido e de complexo cruzamento de culturas", como propõe Perez Gomez. (CANDAU, 2015, p. 11-12).

Nesse sentido, por meio do reconhecimento do/a outro/a e da negociação cultural apresenta-se uma via democrática para a promoção da ecologia de saberes proposta por Boaventura de Souza Santos, destinada a reinvenção da emancipação social baseada na ideia central de que "não há justiça social global sem justiça cognitiva global, ou seja, sem justiça entre os conhecimentos" (SANTOS, 2007, p. 40).

Em contraposição a forma escolar padronizada baseada na hierarquia fundada pela transmissão de conhecimentos, Streck apresenta a compreensão de escola que busca valorizar os patrimônios experienciais de alunos/as e professores/as como aprendentes 
comprometidos/as com a produção de informações originais - agentes de processos educativos assentados, principalmente, na produção de conhecimentos.

A escola, nessa perspectiva, deixa de ser um lugar onde, como queria Comenius, 'todos aprendem tudo", mas onde todos se encontram para conjuntamente produzir conhecimentos novos. A partir de uma perspectiva freireana, nesses encontros todos os saberes são transformados. Não se pretende elevar o nível dos saberes populares ou adaptar os saberes eruditos ao povo, mas de recriar a ambos através do diálogo. Este pode ser entendido ao mesmo tempo como uma relação de negociação porque envolve relações e posições de poder; como uma relação de troca porque se deseja aprender do outro, e como uma situação de dádiva e partilha (STRECK, 2012; p. 21).

Essa visão favorece considerar as artes, especialmente o cinema, na escola como um campo em discussão permanente em que as legitimidades são provisórias, os entes artísticos e os saberes envolvidos são constantemente repensados. O que implica em tornar frequentes as perguntas: que arte está dentro da escola e que lugar ocupam no currículo? Que povos, culturas e artes são privilegiados pela história da arte ensinada nas escolas?

\section{Cinema como arte na perspectiva da educação intercultural crítica}

As brechas decoloniais podem se servir das contradiçōes dos artifícios do poder para plantar suas sementes. Um exemplo disso foi a obrigatoriedade do ensino de Educação Artística surgido com a Lei de Diretrizes e Bases 5.692/1971, como um mascaramento humanístico de uma reforma educacional tecnicista implementada pela ditadura militar.

Essa foi, no entanto, a fissura por onde o ensino de artes penetrou pela primeira vez na educação obrigatória e, vinte e cinco anos depois, na LDBEN 9.394/1996, conquistou o status de disciplina escolar (pois antes era apenas uma atividade educativa) voltada para a formação integral do ser humano e tornou-se um espaço privilegiado na disputa do sensível na escola. Atualmente, mesmo com as perdas advindas da Reforma do Ensino Médio por meio da Medida Provisória no 746 / 2016 - transformada na Lei 13.415, de 16 de fevereiro 2017 -, que tem atentado contra a obrigatoriedade do ensino de Artes no Ensino Médio (tal como para Educação Física, Espanhol, Sociologia e Filosofia), a obrigatoriedade do ensino de artes continua prevista com Artes Visuais, a Dança, a Música e Teatro?.

\footnotetext{
7 Do retrocesso da redação inicial dada pela Medida Provisória no 746, de 2016, em que o ensino da arte reduziu sua obrigatorieda aos segmentos da educação infantil e educação fundamental, retornou-se à previsão anterior de obrigatoriedade a todos os segmentos da educação básica, ainda que na redação atual se tenha
} 
Entretanto, de acordo com a lógica assimilacionista dos conhecimentos escolares de Artes Visuais, as narrativas hegemônicas da história da arte eurocêntrica têm o poder de absorver as tradições artísticas não ocidentais, classificando-as genericamente como Arte Africana, Arte Indígena, Arte Popular, em nome do desenvolvimento do pluralismo cultural. No caso da Arte Indígena e Arte Africana, a diversidade artística e cultural desses povos é eliminada pela compactação empreendida pela transposição didática colonialista que as denomina no singular e mascara a existências de povos indígenas e povos africanos - assim mesmo, no plural.

Por outro lado, a Arte Europeia (termo não utilizado na escola e em livros didáticos e paradidáticos) tem hegemonia no currículo que é organizado a partir de suas manifestações históricas - Arte Greco-Romana, Arte Medieval, Arte Renascentista, Arte Barroca, Arte Acadêmica, Impressionismo, Cubismo, entre outros. No ensino de História da Arte, via de regra, a Arte Indígena e a Arte Africana ocupam lugar no ponto de partida de narrativas histórico-lineares, logo após a Arte Pré-histórica e antes da Arte das Grandes Civilizações, configurando-se assim como "artes do passado", de povos que não existem mais. No caso da Arte do Egito Antigo, não raro a sua grandiosidade é apresentada sem vínculo com o continente africano. (CARDOSO JUNIOR, 2017).

Em Candau (2002, p. 91), verificamos que tal procedimento se encontra de acordo com a abordagem aditiva para afetar o currículo na perspectiva da diversidade cultural com o acréscimo de determinados conteúdos em diferentes disciplinas, mas sem efetivamente alterar a sua estrutura básica pautada na hegemonia de uma lógica monocultural. Essa abordagem aproxima-se daquela denominada por Chalmers (2005) como multiculturalismo celebratório ou multiculturalismo leve (soft) que, ao contrário do multiculturalismo crítico ou insurgente, tem demonstrado reticências quanto à lida com a dimensão híbrida e intercultural da arte nas escolas (2005, p. 248-249).

Dessa forma, temos o que o sociólogo português Boaventura Souza Santos (2010) definiu como a produção da inexistência de conhecimentos e saberes desses povos que somente aparecem no currículo para afirmar a superioridade da cultura europeia.

Para criticar a adoção do que denominou de "diversidade abstrata" nas aulas de artes visuais na escola básica, Macedo (2013) traçou um cenário comum em que a pluralidade cultural é afetada pelo escasso tempo de aula dedicado a essa disciplina nas escolas, o que obriga os/as professores/as a realizarem uma síntese dos seus conteúdos destacando os aspectos mais importantes. A prioridade recai constantemente sobre os

retirado a sua função de "desenvolvimento cultural do aluno", aspecto que esvazia o seu sentido e concorre perigosamente para práticas pedagógicas voltadas para a mera produção artística desprovida das relações com as dimensões de contextualização e leitura/contemplação da arte, desmembrando-se os eixos consagrados pela Abordagem Triangular sistematizada por Ana Mae Barbosa no final dos anos 1980.

(As alterações recentes da LDBEN 9.394/1996 podem ser observadas em: http://www.planalto.gov.br/ccivil 03/ ato2015-2018/2017/lei/L13415.htm) 
principais movimentos da história da arte ocidental (com ênfase para a Pré- História, o Renascimento, Impressionismo, o Expressionismo, o Cubismo, a Arte Pop e a Arte Contemporânea, entre outros ismos) e as atividades plásticas (principalmente, desenho, pintura, colagem, e, em situações mais privilegiadas, fotografia e vídeo). Nesse cenário, os trabalhos com/sobre máscaras africanas e/ou indígenas visam contemplar o multiculturalismo com enfoques que, não raro, sublinham o exotismo e reforçam estereótipos culturais, sem discutirem a relação de poder existente entre representações artísticas ocidentais e não-ocidentais.

$\mathrm{Na}$ perspectiva aqui apontada da interculturalidade crítica, com o foco nas questões atuais dos povos indígenas no Brasil, importa-nos pensar a ocupação das imagens na escola como mobilizadoras de pensamento, na crença de que possam impactar os arquivos coloniais que possuem raízes profundas na cultura escolar. Em Macedo (2013) identificamos uma concepção de ensino/aprendizagem intercultural da arte em contraposição à concepção hegemônica e colonialista pautada pelo universalismo ocidental e orientada para a formação de identidades "forjadas em branco" (referência a hegemonia cultural dos homens brancos). A autora investe contra a história da arte de raiz única - linear e ocidental - que, ao omitir as inerentes pluralidades da arte, reduz as possibilidades do ensino de artes visuais participar ativamente de uma rede de relações e trocas não hierarquizadas de saberes, pensamentos, estéticas, memórias e sensações.

No sentido que temos encaminhado até aqui, cremos ser possível disputar o sentido da Lei no $13.006 / 2014$ e ressignificá-la para tomá-la como outra brecha decolonial com a potência de expandir o ensino de artes na escola, especialmente as artes visuais. Um lócus disciplinar a partir do qual o cinema, como arte audiovisual, pode inserir-se na picada aberta pela nomenclatura que substituiu o termo Artes Plásticas por este se referir a uma produção manufatureira que não dava mais conta da multiplicidade de visualidades produzidas por modos diversos surgidos com a industrialização, principalmente a partir da invenção da fotografia e do cinema.

A lei 13.006/14 tem trazido profundos questionamentos e reflexões pela potência pedagógica e de democratização ao acesso de filmes nacionais ${ }^{8}$ e hoje já temos uma proposta de regulamentação da lei ${ }^{9}$ elaborada por um grupo de trabalho que incluiu membros da sociedade civil, do Ministério de Educação e do Ministério de Cultura entregue ao Conselho Nacional de Educação em maio de 2016 que ainda aguarda posicionamento para sua efetivação.

\footnotetext{
${ }^{8}$ Conferir a coletânea sobre Cinema e Educação: a lei 13006/14 em:

http://www.educacao.ufrj.br/portal/educacao.php?pst=2\&pgn=livros digitais

${ }^{9}$ Ver em: FRESQUET, Adriana. et al. Proposta do Grupo de Trabalho Cinema Escola sobre Formação Docente. In: D'ANGELO, Fernanda Hallak e D'ANGELO, Raquel Hallak. CINEOP: $11^{\text {a }}$ Mostra de Cinema de Ouro Preto - Cinema Patrimônio. $1^{a}$ edição. Belo Horizonte: Universo Produção, 2016, pp. 179-189.
} 
A reverberação da questão indígena na educação, ganha intensidade na interface com o cinema. Os filmes portam pedagogias no sentido aberto do termo porque cifram intervenções históricas que abrem arquivos coloniais que conformam imaginários sobre o que é ser índio no Brasil, dando conta do desconhecimento dos povos indígenas brasileiros, segundo disse o professor da UFMG, André Brasil, em comunicação na CineOP, 2017. Para tal, a seguir vamos trazer uma reflexão final com o filme Martírio. Este filme endereça ao cinema novas demandas. Impele ao cinema a sair de si mesmo. O paradoxo de sair do cinema através do cinema significa ultrapassar embates entre a invenção formal e o engajamento social, acrescenta o pesquisador mineiro, pois Martírio abriga as ações de narrar e intervir.

\section{Martírio, "um filme que o Brasil precisa ver"}

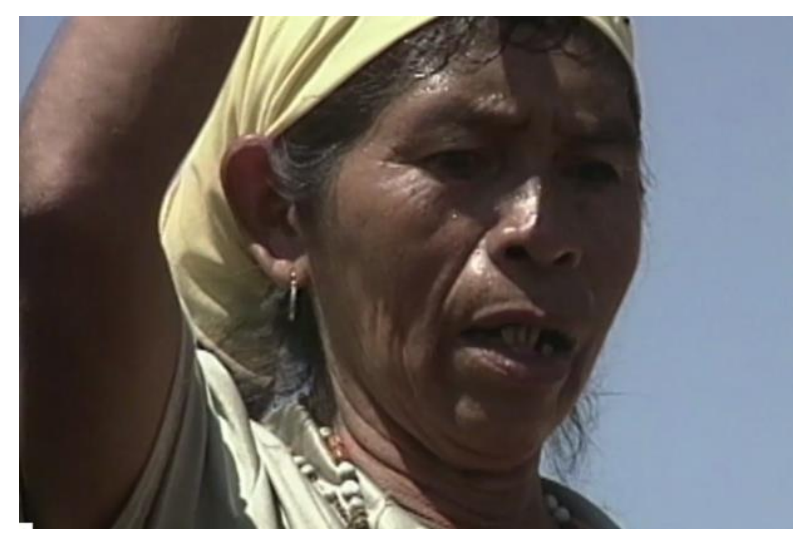

O Sol lhe concedeu o dom do canto.

A Lua também Ihe deu seu poder.

Eu vou cantar para vocês...

Filme Martírio [00:05:29-00:05:36]

"Um filme que o Brasil precisa ver" foi a fala de um jornalista no dia da estreia do filme Martírio, em Brasília, em setembro de 2016, segundo a Carta Capital. O filme de Vincent Carelli, Ernesto Carvalho e Tita, produzido pelo projeto Video nas Aldeias, em 2016, traz uma brecha decolonialista contundente para introduzirmos a interculturalidade na escola. Uma brecha para aprender sobre a história do Brasil do ponto de vista indígena através do cinema. Um cinema que revela o martírio de milhões de brasileiros/as nativos/as desconhecidos/as, negados/as, ocultos/as, silenciados/as, esmagados/as, massacrados/as até os nossos dias. 
O projeto Vídeo nas Aldeias ${ }^{10}$ (VNA) foi criado em 1986 com o objetivo de apoiar as lutas dos povos indígenas para fortalecer suas identidades e seus patrimônios territoriais e culturais, por meio de recursos audiovisuais e de produção compartilhada com os povos indígenas. Trata-se de um projeto precursor da produção audiovisual indígena no Brasil. Surgiu dentro das atividades da ONG Centro de Trabalho Indigenista, como um experimento realizado por Vincent Carelli entre os /as Nambiquara.

Partindo de uma metodologia que consiste em filmar e assistir o filmado em uma permanente troca com outras filmagens produzidas por outras aldeias, foi se gerando uma mobilização coletiva. Hoje boa parte do seu acervo pode ser acessado no catálogo disponível no sítio eletrônico. A primeira oficina de formação na aldeia Xavante de Sangradouro data de 1997. O VNA foi distribuindo equipamentos de exibição e câmeras de vídeo para as comunidades com as quais trabalhava, e assim, simultaneamente, criando uma rede de distribuição dos vídeos produzidos. Entre outras experiências, tem promovido o encontro na vida real dos povos que tinham se conhecido através do vídeo, "ficcionalizando" seus mitos, encurtando distâncias geracionais, geográficas, etc.

Hoje, podemos afirmar que além de um centro de produção de vídeos, o VNA é uma escola de formação audiovisual para povos indígenas. Desde a realização do "Programa de Índio" para televisão, em 1995, até a atual Coleção Cineastas Indígenas (disponível também no sítio eletrônico) passando por todas as oficinas de filmagem e de edição do VNA, em parceria com ONGs e Associações Indígenas, o projeto tem colocado a produção audiovisual compartilhada e a formação no centro das suas preocupações. Uma formação que tem um duplo sentido: instrumentalizar aos/as indígenas para produzirem suas imagens e, ao mesmo tempo, através dessa produção, nos possibilitar a superação do desconhecimento desses povos e suas culturas. Quase um compromisso para engajarmonos nas suas lutas por demarcação de terras e pela preservação dos modos de habitálas.

Em 2000, o VNA se constituiu como uma ONG independente e sua trajetória tem produzido um importante acervo de imagens sobre os povos indígenas no Brasil que já conta com uma coleção de mais de 100 filmes, a maioria deles premiados nacional e internacionalmente, transformando-se em uma referência nesta área.

Dentre esses filmes, a maioria foram produzidos por indígenas, mas há uma trilogia que foi idealizada por Vincent Carelli, da qual já foram produzidos Corumbiara ${ }^{11}$ e Martírio. 0 terceiro filme será Adeus, Capitão. Essa trilogia, diferentemente dos filmes do VNA, é

\footnotetext{
${ }^{10}$ Acessar o sítio eletrônico: http://www.videonasaldeias.org.br/

${ }^{11}$ Corumbiara, Brasil, Vincent Carelli, 117 min. Sinopse: em 1985, o indigenista Marcelo Santos denuncia um massacre de índios na Gleba Corumbiara (RO), e Vincent Carelli filma o que resta das evidências. Bárbaro demais, o caso passa por fantasia, e cai no esquecimento. Marcelo e sua equipe levam anos para encontrar os sobreviventes. Duas décadas depois, "Corumbiara" revela essa busca e a versão dos índios..." Acessível em: https://vimeo.com/101139493
}

Revista Digital do LAV - Santa Maria - vol. 10, n. 2, p. 120 - 139 - mai./ago. 2017 ISSN 1983 - 7348 http://dx.doi.org/10.5902/1983734828951 
baseada no longo trabalho investigativo de Carelli, produto de 30 anos reunindo imagens, onde ele tem colocado lado a lado a luta indígena e as mudanças políticas no país. Os filmes constituem um verdadeiro documento histórico-político que revelam a vida dos povos indígenas subjugados nos seu direitos e garantias constitucionais.

Martírio é um documentário que expressa a profunda indignação de Carelli e que contamina seus/suas espectadores/as. Martírio é um filme-ruína. Vincent nos coloca frente a frente com nós mesmos como ruínas. Ruínas que precisam ser ocupadas com ações, proposições, com movimentos e eventos que colaborem com a luta dos diferentes povos indígenas frente a hegemonia do agronegócio. Ao mesmo tempo, revela a poesia com que os/as Kaiowá e Guarani lutam para existir.

É frequente encontrar imagens com cantos e uma religiosidade sempre presente, com uma cosmovisão profunda, diferente, que coloca em evidência o conceito de perspectivismo de Eduardo Viveiros de Castro, assim como a aposta desse antropólogo brasileiro na antropologia como um gesto de descolonização permanente do pensamento.

Martírio revela por um lado o genocídio de quantitativos humanos inimagináveis, mas por outro lado é tão ou mais grave o que dá a ver sobre o etnocídio de modos sofisticados de ver, pensar e analisar o mundo. Culturas que variam entre os povos indígenas e que precisamos descobrir. Esse é o verdadeiro descobrimento de Brasil que ainda está por acontecer...

Em relação a ação dos pistoleiros, ruralistas e fazendeiros, assim como as ações atrozes que historicamente vem sendo cometidas com os Guaranis, afirma o professor Felipe Milanez $^{12}$ :

Martírio acompanha a trajetória do drama e da violência colonial do capitalismo que atinge os Guarani, desde sua perspectiva histórica nos séculos anteriores, com a Guerra do Paraguai, até o violentíssimo avanço das últimas décadas, marcadas pela crueldade do racismo moderno e a desumanização científica e mediática produzida contra os indígenas nos últimos anos. (MILANEZ, 2016, p. 1)

Para o professor, a "guerra justa" que antes era aplicada para a escravização, agora é justificada pela teologia do progresso e do desenvolvimento, e em louvor à pata do boi e ao sacro grão da soja, produzindo a materialização da desapropriação de suas terras pelo capitalismo.

Para Carelli, presente na 12a CineOP, o Brasil sempre oscilou entre o genocídio e o etnocídio, entre a espada e a cruz. Com Rondón passamos da evangelização para a civili-

\footnotetext{
12 Professor de Descolonização do Conhecimento, Sociedade e Ambiente na Universidade Federal do Recôncavo da Bahia. Ele integra a Rede Europeia de Ecologia Política (Entitle). Sua produção dedica-se a tratar sobre conflitos e resistências ecológicas
} 
zação dos indígenas. O SPI (Serviço de Proteção aos Índios) assumiu o apagamento das línguas indígenas que as Missões haviam iniciado no período colonial, quando os internatos missionários foram dispositivos eficazes para a aculturação de crianças indígenas. A FUNAI é a continuidade desse processo. Passados 500 anos, o processo de colonização ainda não acabou, pois ainda temos populaçōes indígenas isoladas na Amazônia que correm o risco de serem dizimadas. Segundo ele, Martírio é um filme endereçado ao Supremo Tribunal Federal.

O diretor afirma, ainda, em entrevista, sobre o filme:

Martírio é primeiro um surto pessoal, de revolta, de explosão. Você aguenta até certo ponto, mas tem uma hora que você precisar falar: "pô, meu, eu preciso me olhar no espelho" (risos). Você sabe, você conviveu, sabe tudo o que esses flashes significam na vida real. Porque na hora que se toma a decisão, seja a que for, vai ser agora! [Remetendo-se a cenas do filme].

$E$ os filmes também são um processo. Eu nunca imaginei o que seria esse filme. Tinham se passado 15 anos e eu não tinha na época, nos anos 80, 90, uma ideia, uma compreensão global do problema e eu precisava recomeçar, voltar a me aproximar das pessoas. E o meu caminho foi justamente reencontrar os casos, os grupos que eu tinha filmado naquela época que já estavam numa perspectiva de tempo, de história. Como é que cada um estava depois de ter vivido aqueles momentos? Eu fui criado num colégio francês. Queda da Bastilha, Revolução Francesa... mas tenho fascínio pela história do Brasil e aí foi todo um aprendizado e a descoberta de ver a importância, que juntava duas coisas: primeiro, os documentos todos tratando essa trajetória, que faziam do caso algo bastante claro, documentado por registros oficiais, o que não é desprezível como "prova" para o entendimento do processo. $E$, depois, uma reflexão sobre a relação que o Estado brasileiro teria por trás de todo esse processo, com uma intenção, uma costura de ações em relação aos índios, um projeto de nação que pregava a dissolução dos índios, o desaparecimento da diversidade, nas suas várias nuances, nas suas várias expressões, nas suas áreas políticas. $E$ uma repetição dessa relação. E assim virou uma reflexão sobre a relação do Estado brasileiro com os povos indígenas pelo menos nos últimos dois séculos, que é uma coisa completamente desconhecida. Aliás, é uma coisa óbvia para todo mundo que estuda antropologia, etnografia brasileira, mas isso não é de conhecimento público.

Martírio vem também para romper com esse momento tão triste do jornalismo brasileiro. O jornalismo investigativo é raso, quer dizer, a mentira que o ruralista diz, de que os índios querem 40\% do Estado, o Jornal Nacional repete como se fosse dado. Essa coisa revoltante, esse golpe midiático, essa coisa gravíssima que 
é esse ranço jurídico nos marcos temporais que, a partir de outubro de 88, quem estava na área demarcada estava e quem não estava não está mais. Parece brincadeira de roda-roda, sem parar, e que é um golpe jurídico do Supremo, que é também inaceitável, do qual os Guarani-Kaiowás são as grandes vítimas. Há outros. Há outros. Há os povos que não estão contemplados nem na Constituição de 88... (FRESQUET \& PIPANO, 2017, p. 181)

A crença nas imagens e seu poder de salvar ou matar nesse contexto em que vivemos, é uma crença que implica em uma certa ingenuidade, mas que fica sob rasura. Estas são imagens que se produzem e constituem uma espécie de intervenção. Consideramos que elas portam algo de incompletude e é nessa incompletude, no inacabado delas, que cabe a participação ativa e criativa da leitura das mesmas onde todos enquanto espectadores podemos participar e imprimir nossos significados e sentidos. Tratam-se de "imagensruinas", como afirma um dos seus diretores, Ernesto Carvalho [comunicação CineOP/2017], que são produto de uma acúmulo inacabado de desejos. Essas imagens se tornam potentes quando são ocupadas, e elas são ocupadas ao serem produzidas, ao serem rearticuladas na montagem, ou até mesmo quando a câmera ocupa o lugar do escudo em defesa da demarcação das terras indígenas e se torna testemunha de suas vidas e de suas lutas.

\section{O que aprendemos com Martírio na escola?}

Há um antecedente no próprio cinema que quiça tacitamente serviu de inspiração a toda a obra do VNA. Trata-se de uma passagem muito curta, de apenas 1'40", do filme The passenger ${ }^{13}$, de Michelangelo Antonioni (Itália, 1975). Nesse trecho do filme um jornalista, o Sr. Locke, interpretado por Jack Nicholson, entrevista um curandeiro africano com o seguinte diálogo.

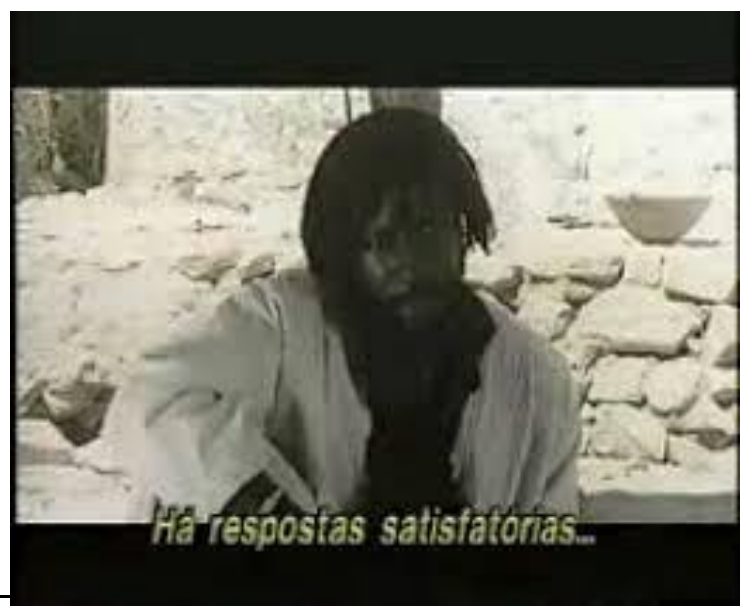

\footnotetext{
${ }^{13}$ No Brasil, o filme foi traduzido como Profissão Repórter.
} 
Locke: - Ontem quando o filmamos você disse que foi criado para ser curandeiro. Não é incomum para alguém como você ter vivido tantos anos na França e na Iugoslávia? Isso o fez mudar com respeito a certos costumes tribais? Eles não Ihe parecem falsos agora e talvez errados para a tribo?

Curandeiro: - Há respostas satisfatórias para todas as suas perguntas, mas não entende como pode aprender pouco com elas. Suas perguntas revelam muito mais sobre você mesmo do que minhas respostas sobre mim. Eu as fiz com sinceridade. Sr. Locke podemos conversar... não apenas sobre o que o senhor acha sincero, mas também sobre o que eu acredito ser honesto. Sim, claro, mas... [corta, e o curandeiro se levanta, toma a câmera do jornalista e a gira enquadrando o jornalista Locke.] Agora você pode fazer a entrevista. Pode fazer as mesmas perguntas que antes.

Nessa cena temos exatamente o gesto que Carelli fez de sua vida, de sua obra, preciosa e com presença precisa no filme Martírio. Girar a câmera e deixar que o enquadramento seja dado por quem é o alvo de interesse. Não são as suas respostas que interessam, mas sim a sua maneira de filmar, as suas escolhas, a sua voz em off e o que eles desejam saber, inclusive do mundo que os maltrata e submete. Como soam as perguntas e as respostas quando a câmera se desloca do lugar do olhar colonizador?

Martírio é isso: um deslocamento geográfico, histórico, político, ético e pedagógico.

Uma primeira aprendizagem que emerge gritante é a divergência de versões acerca da história do país. Aprendemos sobre vidas outras, modos outros de habitar as terras, trabalhá-las, povoá-las. Maneiras outras de produzir alimentos, saúde e conhecimentos. Maneira outra de transmitir os saberes e as práticas no ato de cantar, imprimindo na voz uma forma sensível e espiritual de aprender coletivamente sobre a própria história.

Aprendemos, na montagem, a comparar o que simultaneamente acontece no Congresso Nacional, com falas como a da senadora Katia Abreu (PSD/TO), no plenário, opondo a questão indígena à "paz" que o trabalhador do campo demanda para trabalhar.

O cinema produzido por e com indígenas não carrega nenhum essencialismo de um outro tipo de cinema que, muitas vezes, uma certa antropologia colonialista pretende encontrar. O cinema, como outras formas de expressão, cria pontes, encontros entre diversas aldeias e, inclusive, com a cultura ocidental.

Fica assim um desejo de presença do cinema e da interculturalidade na escola, tomados pela inspiração da potência de Martírio e da sabedoria vanguardista do fragmento de Antonioni. Buscando dessa forma fugir de essencialíssimos, girando a câmera para a emergência das visualidades dos estudantes, registrando os cantos, os silêncios, contrastando na montagem a beleza com a hipocrisia, o espiritual com o profano. É esse o nosso anseio sobre o encontro do cinema com a escola, realizado em um cenário de 
forte teor político, ético e estético. Um cinema que ao ser projetado atice o diretor criativo e oculto existente em cada espectador. Um cinema que incite a produção audiovisual escolar, mesmo com dispositivos móveis de comunicação, ou com pequenas câmeras de fotografia, ou até mesmo com as imagens em movimento produzidas pela montagem de fotografias feitas com caixinhas de fósforos com a técnica de pinhole. Um cinema expandido sob o risco do que os/as estudantes escolham filmar. E que das desigualdades que suas imagens explicitem, ou do eventual apagamento ou disfarce das diferenças que elas revelem, assim como do mundo enquadrado por eles/as de distintas maneiras, nos deixem ver/saber sobre aqueles/as que sonham em habitá-lo

\section{Referências}

BRASIL. Lei no 9.394, de 20 de dezembro de 1996. Lei de Diretrizes e Bases da Educação Nacional. Brasília, DF: Senado, 1996. BRASIL. Lei no 9.394, de 20 de dezembro de 1996. Lei de Diretrizes e Bases da Educação Nacional. Brasília, DF: Senado, 1996.

CANDAU, Vera. Multiculturalismo e Educação: a construção de uma perspectiva. Cidadania e Pluralidade Cultural: questões emergentes. In: CANDAU, V. (Org.) Sociedade, Educação e Cultura(s): Questões e Propostas. Petrópolis, RJ: Vozes, 2002. . (org.) Didática: Questões Contemporâneas. Rio de Janeiro: Forma \& Ação, 2009.

V. M.; OLIVEIRA, L. F. Pedagogia decolonial e educação antirracista e intercultural no Brasil. Educação em Revista, Belo Horizonte / MG, v. 26, n.01, p. 15-40, abril 2010b.

V. "Ideias-Força" do pensamento de Boaventura Souza Santos e a educação intercultural. IN: CANDAU, V. (org.) Interculturalizar, descolonizar, democratizar: uma educação "outra"? Rio de Janeiro, RJ: 7Letras, 2016.

FRESQUET, Adriana e PIPANO, Isaac. Entrevista a Vincent Carelli. 12a Mostra de Cinema de Ouro Preto. Cinema Património. Ouro Preto: Universo, 2017.

CARDOSO JUNIOR, Wilson. Interculturalidade e ensino de artes Visuais no Colégio Pedro II. Tese de doutorado. PPGE-PUC/RJ. 2017.

CASTRO-GOMEZ, Santiago. La poscolonialidad explicada a los niños. Bogotá: Universidad Del Cauca, Instituto Pensar, 2005.

CHALMERS, Graham. Seis anos depois de Celebrando o Pluralismo: Transculturas visuais, educação e multiculturalismo crítico. In: BARBOSA, A. M. (org.) Arte/Educação contemporânea: consonâncias internacionais. São Paulo: Cortez, 2005.

FLEURI, Reinaldo Matias. Políticas da diferença: para além dos estereótipos na prática educacional. Educação e Sociedade, Campinas, v. 27, n. 95, p. 495-520, 2006. 
FORQUIN, Jean-Claude. O currículo entre o relativismo e o universalismo: dialogando com Jean Claude Forquin. In: Dossiê "Políticas Curriculares e Decisões Epistemológicas". Educação e Sociedade, no 73, ano 2000.

GOMES, Nilma Lino. Diversidade e Currículo. In: BRASIL. Ministério da Educação. Secretaria de Educação Básica. Indagações sobre o currículo. Diversidade e Currículo.

Brasília, $2007 . \quad$ Disponível em: http://portal.mec.gov.br/seb/arquivos/pdf/Ensfund/indag4.pdf

MACEDO, J. G. Identidades forjadas em brancos: ensino de arte e interculturalidade' Doutorado em ARTES Instituição de Ensino: Universidade Federal de Minas Gerais, Belo Horizonte, 2013.

MIGNOLO, Walter D. La colonialidad: La cara oculta de la modernidad. In: MIGNOLO, Walter. América Latina lo contrario. USA: Duke University Press, 2010.

MILANEZ, Felipe. Martírio: um filme para indignar Brasília. Em: Carta Capital. Accesado em: 01/07/2017; publicado 22/09/2016 17h53.

QUIJANO, Anibal. Colonialidad del poder y classificación social Journal of woeld-systems research, v. 11, n. 2, p. 342-386, 2000 / QUIJANO, Anibal. Colonialidad y modernidadracionalidad. Disponível em: <http://pt.scribd.com/doc/36091067/Anibal-QuijanoColonialidade-e-Modernidade-Racionalidade.

SANTOS, B. S. Para além do pensamento abissal: das linhas globais a uma ecologia de saberes. IN: SANTOS, Boaventura Sousa \& MENESES, Maria Paula [Orgs.]. Epistemologias do Sul. São Paulo: Cortez, 2010.

STRECK, D. R. Qual o conhecimento importa? Desafios para o currículo. Curriculo sem frontera, v. 12, n. 3, p. 8-24, Set/Dez 2012. Disponível em: http://www.curriculosemfronteiras.org

TUBINO, Fidel. La interculturalidad crítica como proyecto ético-político. Encuentro Continental de Educadores Agustinos. Lima (Perú), enero 2005. Disponível em: http://oala.villanova.edu/congresos/educacion/lima-ponen-02.html

WALSH, C. Interculturalidade Crítica e Pedagogia Decolonial: in-surgir, re-existir e reviver. In: CANDAU, V. M. (org.) Educação intercultural na América Latina: entre concepções, tensões e propostas. Rio de Janeiro: 7Letras, 2009.

WALSH, C. Notas pedagógicas a partir das brechas decoloniais. IN: CANDAU, Vera (org.) Interculturalizar, descolonizar, democratizar: uma educação "outra"? Rio de Janeiro: 7 Letras, 2016.

\section{Filmografia}

Martírio (Carelli, Brasil, 2016)

The passenger (Antonioni, Itália, 1975)

Revista Digital do LAV - Santa Maria - vol. 10, n. 2, p. 120 - 139 - mai./ago. 2017 ISSN 1983 - 7348 http://dx.doi.org/10.5902/1983734828951 
i Professora associada da Faculdade de Educação da Universidade Federal do Rio de Janeiro é membro do Programa de Pós-Graduação em Educação (FE/UFRJ). Coordena o grupo de pesquisa CINEAD/LECAV e o programa de extensão Cinema para aprender e desaprender; atividades conjuntas com a Cinemateca do Museu de Arte Moderna do Rio de Janeiro (MAM-Rio).

ii Professor assistente da Universidade Federal do Rio de Janeiro. Tem experiência na área de Educação, com ênfase em Ensino da Arte, atuando principalmente com os temas de ensino da arte, educação, interculturalidade e imagem.

Enviado em: 06 de junho de 2017.

Aprovado em: 13 de julho de 2017. 